\title{
CONTRIBUIÇÕES À EDUCAÇÃO TÉCNICO-CIENTÍFICA EM HEISENBERG E HEIDEGGER
}

\author{
Paulo Rogério Garcez de Moura* \\ André Luís Silva da Silva* \\ Diogo Onofre Gomes de Souza** \\ José Cláudio Del Pino ***
}

\begin{abstract}
RESUMO: Apresentaremos as possíveis aplicações pedagógicas das suas reflexões, como a utilização da imprecisão científica de Heisenberg e da concepção de técnica em Heidegger, a partir da análise histórico-filosófica dos seus escritos, tomando-os como fundamentação a necessária e significativa melhoria da educação técnico-científica.
\end{abstract}

Palavras-chave: educação científica, técnica, hermenêutica, indeterminação, concepção existencial.

Resumen: Vamos a presentar las posibles aplicaciones pedagógicas de sus reflexiones, como el uso de la inexactitud científica de Heisenberg y el diseño técnico de Heidegger, a partir del análisis histórico-filosófico de sus escritos, tomándolos como la base necesaria y una mejora significativa de la educación técnica científica.

Palabras-clave: enseñanza de las ciencias, técnica, hermenéutica, indeterminación, concepción existencial.

\section{Introdução}

Heisenberg (1980) contribuiu tanto para o estabelecimento da mecânica quântica quanto para a reflexão teórica por meio da produção filosófica na medida em que abordou dentre outros assuntos, a questão do método das ciências naturais, a essência da matéria e o que se refere às observações dos fenômenos da

\footnotetext{
" Professores do Instituto Est. Educ. Prof. Annes Dias/9a CRE, Doutorandos em Educação em Ciências/UFRGS - paulomouraquim@bol.com.br; andreluis.quimica@ibest.com.br.

*** Professor Doutor em Medicina/Bioquímica/UFRGS - Professor Coordenador do PPG Educação em Ciências/UFRGS - diogo@ufrgs.br.

*** Professor Doutor em Engenharia de Biomassa/Química/UFRGS - Professor Orientador do PPG Educação em Ciências e PPG Química/ UFRGS - delpin@yahoo.com.br.

Projeto apoiado pelo CNPQ.
}

MOURA, Paulo Rogério Garcez de; SILVA, André Luís Silva da; SOUZA, Diogo Onofre Gomes de; DEL PINO, José Cláudio. Contribuições à educação técnico-científica em Heisenberg e Heidegger. Revista Sul-Americana de Filosofia e Educação. Número 20: maio-out/2013, p. 179-199. 
natureza. Esses escritos filosóficos tratam das questões que apontam para novas investigações no campo da física teórica e experimental.

Para Heisenberg a física quântica requeria que a percepção das partículas do microcosmo, como sendo objetos simplesmente calculáveis e existentes em si mesmos, fosse substituída pela análise do processo das suas interações recíprocas, na qual o próprio sujeito observador interfere e está implicado pela sua ação de medição e cálculo. Em decorrência, o princípio de incerteza se expressa em que um estado de movimento se identifica somente quanto à calculabilidade estatística ou da posição, ou da grandeza do movimento (EISBERG \& RESNICK, 1979; GASIOROWICZ, 2007; HEISENBERG, 1990).

Heidegger, por sua vez, após ressaltar o existente humano como ser-nomundo a encontrar entes determinados e tomados como objeto pela perspectiva científica trata posteriormente da questão da técnica. Ele compreendeu que a física quântica, incorporando a física clássica, permaneceu imutável no que concerne ao projeto prévio de ciência investigativa da natureza, como realização científica em termos de teoria. A ciência e a técnica, então, permaneceram como modos de acesso à natureza em sua plenitude inesgotável, o que faz com que ela seja incontornável e inacessível mesmo com a utilização técnica dos recursos da cientificidade (DUBOIS, 2004; HEIDEGGER, 2006).

Para Heidegger, a física quântica prescinde dos pressupostos fundamentais da física clássica e problematiza e impede fundamentalmente uma determinação geral da natureza. A partir, segundo Cassirer, dessa impossibilidade decorrente das discussões na física atômica, é levado a formular questões fundamentais sobre o sentido de toda a atividade científica, como diz:

A mecânica quântica representa o renascimento, a renovação e a confirmação do ideal pitagórico clássico, de modo que quando se fala na objetividade do número, tratase dele como um instrumento para a descoberta da natureza. Para ele, ao desenvolver a teoria geral da relatividade, Einstein voltou à geometria de Riemann, estando convencido que precisava lidar com possibilidades lógicas a fim de lidar com a descrição de fenômenos naturais. E mais, precisava de plena liberdade na construção de várias formas do simbolismo matemático, no intuito de dotar o pensamento 
físico com todos os instrumentos intelectuais (CASSIRER, 1972).

Heidegger afirmou que Heisenberg pensava filosoficamente ao instaurar novas maneiras de interrogar a natureza, ao se manter antes de tudo em questionamento. Argumentou que ao perguntar pela natureza pelo viés técnicocientífico não pretendia substituir e nem melhorar as ciências, mas que deveria tomar a seguinte decisão: é a tecnicidade moderna a medida e padrão para o saber científico? Este saber inicia-se com a ciência ou é limitado por fundamentos subjacentes à própria vida?(HEMPEL, 1990).

Assim sendo, no ato de questionar, na elaboração conceitual das respostas, a compreensão sobre ciência vai se ampliando, também pela necessária aproximação com outras áreas do conhecimento humano, podendo contribuir aos aspectos educacionais das ciências naturais. Pensar ciência a fim de compreendêla, sob a ótica interdisciplinar, incorporando contribuições de outros saberes, é uma das tarefas da educação em ciências. Logo, conforme destaca Cachapuz:

A educação em ciências enquanto área emergente do saber em estreita conexão com a ciência necessita da epistemologia para uma fundamentada orientação, devendo ser ainda um referencial seguro para uma adequada construção das suas análises. A epistemologia ao pretender saber das características do que é específico da cientificidade e tendo como objeto de estudo a reflexão sobre a produção da ciência, sobre seus fundamentos e métodos, sobre seu crescimento, sobre os contextos de descoberta, não constitui uma construção racional isolada. Ela faz parte de uma teia de relações, muitas vezes oculta, mas que importa trazer ao de cima numa educação científica que ao refletir sobre suas finalidades, sobre seus fundamentos e raízes, sobre as incidências que produz no ensino praticado $e$ nas aprendizagens realizadas pelos alunos se esclarece na própria orientação epistemológica que segue (CACHAPUZ, 2011).

Trataremos, portanto, das potencialidades teórico-reflexivas em Heisenberg e Heidegger à educação técnico-científica, abordando as questões da tecnicidade ocidental, sob o aspecto da compreensão hermenêutico-fenomenológica. 
Revisão de Literatura

Quando se deseja a proposição de uma definição para a ciência, nota-se o quanto é complexo fazê-lo. Todos creem saber o que é a ciência, mas quando temos de defini-la é que percebemos nossas limitações. A ciência, etimologicamente scientia (saber), que os gregos designaram $\varepsilon \pi \sigma \sigma \tau \eta \mu \eta$ (epistêmê:conhecimento) por oposição a $\gamma v \omega \dot{\mu} \mu \eta$ s (gnômês.opinião), é conhecimento, é uma das modalidades privilegiadas que assume o conhecimento humano (CAPRA, 1996).

Do mesmo modo que a maioria dos professores vê as ciências, eles a transmitem, e o conhecimento científico é, hoje em dia, visto por muitos como um conhecimento infalível, passando a ideia de que tudo o que é cientificamente comprovado merece atenção e pode trazer benefícios à população (NARDI, 2008). Mesmo que possa parecer não crível, é preciso acentuar que não devemos pensar a ciência como pronta e acabada, como uma nova e dogmática religião, como o deus saber imperando no novo milênio, mas a marca da verdadeira ciência, da ciência dos nossos dias, é a incerteza. Como afirma Heisenberg:

Os fenômenos percebidos mediante os sentidos, mediante a ação conjunta dos processos individuais dos átomos, poderiam levar a se considerar as leis da natureza unicamente como leis estatísticas. Assim, tais leis estatísticas, explica Heisenberg, poderiam conduzir a proposições com alto grau de probabilidade, ainda que fossem teoricamente admitidas exceções poderiam ser compreendidas como certeza (HEISENBERG, 1980).

Antigamente a ciência nos falava de leis eternas, hoje nos fala de história do Universo ou da matéria e nos propõe sempre novos desafios que precisam ser investigados. Este é o universo das probabilidades, e não das certezas.

\section{Abordagens em Heisenberg}

Werner Karl Heisenberg (1901-1976), físico alemão, um dos fundadores da mecânica quântica, foi aluno de Arnold Sommerfeld e assistente de Max Born e trabalhou com Niels Bohr. Desenvolveu a mecânica matricial e contribuiu 
decisivamente na construção e desenvolvimento da física atômica, a partir da antiga teoria quântica de Max Planck.

No ano de 1927, em Leipzig, Heisenberg enunciou o Princípio da Incerteza ou da Indeterminação, segundo o qual é impossível medir simultaneamente e com precisão absoluta a posição e a velocidade de uma partícula, isto é, a determinação conjunta do momento e da posição de uma partícula contém erros não menores que a constante de Planck. Esses erros são desprezíveis em âmbito macroscópico, porém se tornam importantes para o estudo de partículas atômicas. Assim, duas grandezas podem ser determinadas exatamente de forma separada, quanto mais exata for uma delas, mais incerta se torna a outra. $\mathrm{O}$ cientista recebeu o Prêmio Nobel de Física, em 1932, pelas suas contribuições à mecânica quântica, cuja aplicação possibilitou a descoberta das formas isotópicas do hidrogênio. Também realizou pesquisas sobre a teoria das partículas elementares, a respeito da estrutura do núcleo atômico, da hidrodinâmica das turbulências, dos raios cósmicos e do ferromagnetismo (HERMANN,1976).

Heisenberg contribuiu tanto para o estabelecimento da mecânica quântica quanto para a reflexão teórica por meio da produção filosófica na medida em que abordou dentre outros assuntos, a questão do método das ciências naturais, a essência da matéria e o que se refere às observações dos fenômenos da natureza. Esses escritos filosóficos tratam das questões que apontam para novas investigações no campo da física teórica e experimental, tais como a não exatidão científica, ou seja, a subordinação da teoria ao seu observador.

O entendimento padrão da tradição científica é que o conhecimento seja inteiramente objetivo, sem papel para a interpretação histórica e humana; que tal conhecimento seja demonstrativo no sentido que os eventos reais futuros possam ser deduzidos às condições reais previamente observadas, por força da própria teoria, sem recorrer ao papel do sujeito que questiona.

Segundo Heisenberg (1980), as raízes históricas modernas das ciências naturais se localizam no período do Renascimento Humanista, quando aparece a ideia de acesso à natureza. Heisenberg considera a esse respeito Leonardo da Vinci (1452-1519), sobretudo no que se refere ao conceito moderno da experiência e 
quando diz que experimentar é interrogar a natureza relativamente a uma teoria propriamente estabelecida para verificar se esta é confirmada ou refutada pela experiência.

Esse comportamento teórico padrão tem se mostrado insuficiente para dar sentido à história da ciência e das práticas de realização das pesquisas científicas. Também não tem respondido como teorias ideais (matemáticas) possam explicar dados empíricos, nem como tais dados justificam com algum grau de certeza as teorizações sobre o mundo real objetivo (HEISENBERG,1990).

Há quase um século o categórico formalismo científico fora superado. Suas leis, seus conceitos, suas classificações, não podem mais ser apresentados aos alunos como verdades absolutas. Nenhum evento é independente, nenhum conhecimento é imutável. A ciência não pode ser vista como algo estanque, encerrada em si mesmo e capaz de atender as necessidades colocadas e não carregar consigo a condição de responder na totalidade as questões dadas, conforme diz:

Permitir extrair da história das ciências os problemas significativos e colocar o aluno em condições de abordá-los, promovendo situações de aprendizagem que permitam aos alunos vivenciar a construção do conhecimento científico (LOGUERCIO et al, 2006).

A ciência diferencia-se das demais áreas do conhecimento humano exatamente por sua fluidez, sua capacidade de renovação e adaptação aos novos fatos conhecidos. E isso é digno de valor: a utilização desses fatos para construção do conhecimento, e não adaptação dos fatos, como segue:

A ciência atual não permanece estática como na Renascença, mas num constante processo de ir e vir, de construir e reconstruir. Nessa busca incessante, a ciência tem como objetivo primordial tentar tornar inteligível o mundo $e$ atingir um conhecimento sistemático do universo (KOCHE, 1982).

Nesse sentido, não se pode temer afirmações como "a não exatidão do conhecimento científico pode ser utilizada como ponto de partida para a almejada formação do aluno pesquisador"; "poderá o professor buscar a construção junto a seu aluno em conhecimento pessoal, em individualidade, de modo que se 
contemple sua atual realidade contextual, fazendo-o integrante de um processo em construção, indo muito além de receptadores de informações abstrativas”. E ainda: "cabe certamente ao educador se questionara esse respeito, uma vez que pode utilizar da possibilidade evolutiva das ciências positivamente, despertando a curiosidade investigativa daqueles que o ouvem".

O fato de se afirmar que a ciência está fundamentada em sua indeterminação pode, em um primeiro momento, repercutir com estranheza, pois se entende justamente o contrário, que uma afirmação científica não pode estar equivocada. Entretanto, estar à ciência fundamentada em sua indeterminação é considerar a sua possibilidade de evolução, de aprimoramento, e de constante construção. E é nesse sentido, para Popper, que uma teorização científica não pode ser dogmática, como diz:

Quanto mais aprendemos sobre o mundo e mais profunda a nossa aprendizagem, mais consciente, específico, e articular será nosso conhecimento do que não sabemos, o nosso conhecimento da nossa ignorância. Para isso, na verdade, é a principal fonte de nossa ignorância - o fato de que nosso conhecimento pode ser apenas finito, enquanto nossa ignorância deve necessariamente ser infinita (POPPER, 1982).

As instituições de educação possuem uma funcionalidade alicerçada no paradigma das certezas, provendo uma base geral para o seu funcionamento. A estabilidade e a continuidade são essenciais. No entanto, percebe-se que demasiada estabilidade ameaça a continuidade. O mesmo sucede com o ser humano, pois o sujeito que não se renova embrutece e geralmente é excluído da dinâmica social. Para o indivíduo e para a sociedade, o conservadorismo é tão importante para a sua manutenção e funcionamento quanto o é a renovação para a sua continuidade. A renovação constitui um risco necessário.

A escola mantém-se pelas repetições de normas, valores e sanções sociais. A avaliação é prevista e se faz por meio de instrumentos que aferem a reprodução do que foi ministrado em determinado período. Tal tipo de instrumento está suficientemente padronizado, e tanto os alunos como os professores sabem suas regras (SANTOS 2002). 
Entretanto, o conhecimento não está estagnado, ele é dinâmico. Seu desenvolvimento, ao longo da história, consolidado nos modos de pensar da humanidade, tem-se orientado pelo paradoxo clausura-abertura. A ciência, fenômeno marcante da era contemporânea, constrói e desconstrói a sua própria construção. $\mathrm{Na}$ ação pedagógica, os professores tem a concepção de que os objetivos educacionais e o planejamento didático precisam estar alicerçados na certeza. Mas a incerteza ou indeterminação diz respeito às características dinâmicas do sujeito, do conhecimento e da sociedade humana, e assim a certeza construída terá sempre uma janela aberta à incerteza.

A interferência do observador é algo que desde o princípio de uma análise investigativa deve ser considerada. Segundo Heisenberg, o conceito de realidade no século XIX estava relacionado aos conceitos fundamentais de espaço, tempo, matéria e causalidade, e dizia respeito a fenômenos que percebemos pelos nossos sentidos ou, ainda, àqueles que podemos observar devido à disponibilidade de instrumentos refinados que a ciência técnica veio a proporcionar (HEISENBERG, 1981).

Sabemos hoje, entretanto, que a medição, pura e simples, não autoriza um valor numérico daquilo que objetivamente fora medido. $\mathrm{Na}$ experimentação, o número que emerge a partir de uma medida, não consiste em um objeto em si mesmo, mas possui suporte em uma teoria que o antecede. E mais uma vez não se pode aqui operar-se a exclusão do observador da experiência. No ofício de ensinar, ao invés de entendermos a medição como algo a parte do observador, podemos destacar o sujeito como diretamente implicado no ato de medir, pois, por natureza, não poder se desvencilhar daquilo que mede. O que se pretende que ocorra é uma integralidade entre o pensamento e a realidade como um todo.

Isso leva Bohr a refletir acerca da ampla dificuldade entre a distinção sobre o que é a realidade observada e quem é o observador, sendo a todo instante transmitido em sala de aula à obviedade da separação entre o objeto observado $e$ o sujeito que o observa. Esse pressuposto de que é possível traçar uma distinção nítida entre o comportamento do objeto e os meios de observação foi protagonizado por Descartes e consiste na base da física clássica (BOHR,2000). 
Entretanto, mais de três séculos após, se lida hoje com uma nova visão epistemológica, a relação indissociável do sujeito-objeto. Segundo Lopes, tal indissociabilidade é amplamente verificada quando tratamos dos objetos atômicos individuais, forçosamente modificados pelos instrumentos de medida, $e$ mais:

Uma concepção empirista-indutivista se caracteriza pela crença de que todo o conhecimento tem sua origem na experiência, sendo a observação o único ponto de partida para o desenvolvimento científico. Esta permite a formulação de enunciados singulares que, por inferências (indução) $e$ generalizações, se converterão em enunciados gerais ou leis universais. Seus pressupostos derivam da visão positivista do conhecimento e do método científico experimental (LOPES, 2007).

Em relação à linguagem científica, Mortimer (1996), ao utilizar a fórmula química da água como exemplificação, afirma que todas essas considerações nos levam a concluir que a fórmula química da água $-\mathrm{H}_{2} \mathrm{O}-$ é um importante instrumento para explicar várias de suas propriedades, inclusive as mais notáveis e incomuns. No entanto, a fórmula nada mais é que uma representação da substância. Como tal, devemos usá-la, apropriando-nos das informações que ela pode nos fornecer, mas tomando o cuidado de não confundi-la com a realidade mesma da substância água, muito mais complexa e profunda do que aquilo que duas letras do alfabeto e um número permitem antever.

Heisenberg se deparou com o questionamento sobre a linguagem da física ao analisar um problema fundamental: a impossibilidade dos novos aspectos da natureza oriundos da técnica das novas medições experimentais, serem descritas em termos de conceitos da vida cotidiana. Pois, para ele, a exposição dos resultados de uma dada experiência somente é válida quando suas explicações são a todos compreensíveis. Temos então aqui um ponto fundamental de discussão: a linguagem científica. Heisenberg considera que, então, a partir do ideal platônico, as estruturas do microcosmo não existem efetivamente como algo material, mas sim como uma forma matemática ou uma construção intelectual, a partir da qual o mundo pode ser uniformemente inteligível como uma simetria matemática, uma imagem ou uma ideia (HEISENBERG, 1980). 
Vemos, assim, que a própria forma de comunicação utilizada pelo cientista em linguagem clara se constitui em um critério de seu próprio grau de entendimento. Para Heisenberg, uma das mais importantes características do desenvolvimento e análise da física moderna é a experiência de demonstrar que os conceitos da linguagem cotidiana, apesar de toda imprecisão quântica, é decorrente de uma idealização a partir somente de alguns grupos pontuais de fenômenos (HEISENBERG, 1981).

No evento promovido pelo Centro Internacional de Física Teórica (1968) em Trieste, Heisenberg menciona seu encontro com Einstein, no ano de 1926, em Berlim por ocasião da realização de uma palestra sobre mecânica quântica, quando o diálogo entre ambos tratou da relação entre teoria e observação. Einstein the perguntou qual seria a filosofia subjacente à teoria que Heisenberg havia tratado, conforme relata:

Disse ele [Einstein]: "A possibilidade que se tem de observar ou não uma coisa depende da teoria que se usa. É a teoria que decide o que pode ser observado. [...] A observação significa que construímos algum vínculo entre um fenômeno e nossa compreensão do fenômeno". [...] Assim, ele insistiu em que é a teoria que decide sobre o que pode ser observado (HEISENBERG, 2009).

Os conceitos de linguagem natural estão repletos de associações diretas com a realidade, com as situações cotidianas que constituem as experiências da vida. $\mathrm{E}$ essa imprecisão da linguagem não deve consistir em uma limitação para a compreensão de um fenômeno de natureza científica. Deve compor um meio de desenvolver uma compreensão pessoal a respeito das ligações entre o aquilo que deseja demonstrar e a própria forma de assimilação de quem se propõe a fazê-lo. Para Maturana, as diferentes palavras que utilizamos na vida cotidiana não pretendem ser precisas, mas correspondem a diferentes operações que realizamos no viver, e nunca são, na verdade, arbitrárias, e sempre revelam coerências do viver no âmbito de nossa atuação como ser humano (MATURANA, 1997).

\section{Abordagens em Heidegger}


Martin Heidegger (1889-1976) foi um dos mais importantes filósofos do Século XX, seja pela sua posição dada a tradição metafísica, seja pelo tratamento empregado da questão diretriz da filosofia desde Platão e Aristóteles - o problema do ser - através do método fenomenológico. O pensamento de Heidegger surgiu a partir da época da Primeira Guerra Mundial, sendo particularmente marcado pela apresentação da questão ontológica e da sua analítica existencial com a publicação de Ser e Tempo (1927). Sua composição se estendeu de 1923 a 1926, período em que seus cursos têm aspectos de redações diferentes, porém estando conectados e enraizados nesta obra fundamental. A recepção da filosofia heideggeriana tem alcançado maior destaque com a atual publicação das suas Obras Completas (Gesamtausgabe), ampliando o acesso e o tratamento das temáticas, como a técnica e a ciência. Em Heidegger a relação entre ontologia e descrição dos domínios dos entes fundamenta a elaboração do conceito existencial de ciência (SAFRANSKI, 2000).

Trataremos do pensamento de Heidegger sobre as possíveis abordagens da técnica desde o movimento da. Viragem (Kehre) nos anos de 1930 até a década de 1950. Nesta fase, o docente universitário e também filósofo se ocupou da questão da metafísica que desde a filosofia grega marcou o ocidente quando instituiu determinado ente como absoluto, sendo como capaz de figurar como princípio $e$ causa do ser de todos os entes (GLAZEBROOK, 2000).

Heidegger imprimiu nova orientação às suas concepções existenciais ao tomar a tematização da temporalidade e da historicidade do "ser-aí ou existente humano" (Dasein) como ponto de partida. A partir da sua ontologia fundamental, ao questionar ter-se-ia dado à possibilidade de clarear as precondições do modo de "ser-no-mundo", enquanto meio de acesso ao sentido dos dados disponíveis. Desta forma, cada modo de pensar pode ser visto como histórico em seus avanços e resultados, assim como nos recuos no ato de questionar. Contudo, mesmo sendo importantes, tais recuos passam despercebidos à maior parte do tempo.

A reflexão heideggeriana sobre as ciências empíricas, em sua ontologia fundamental, tem como base a "analítica do ser-aî" que concentra as atenções nas possibilidades das ciências ônticas. Barash (1995) argumentou que tal posição de 
Heidegger sobre a condição de pensar provém da metafísica advinda da filosofia grega. Ao tratar da possibilidade do "ser-aî" poder apropriar-se da compreensão, não são primordialmente colecionadora e classificadora de conhecimentos, ela pode se tornar clara por uma espécie de abertura e de renovar a verdade sobre a natureza.

No período seguinte à Viragem(Kehre),Heidegger apresenta um novo desafio à herança da racionalidade ocidental. Ele traz à reflexão a temática do desocultamento da essência da técnica moderna e do seu reconhecimento como o destino do ocidente. Apesar de ter insistido mais explicitamente neste assunto, sua preocupação relativamente à racionalização sistemática do mundo foi expressa bem mais cedo. Em Heidegger a técnica e a metafísica modernas são modos de ser que se encontram entrelaçados, tendo ambos à mesma origem na recusa de pensar o ser à medida que elas tentam sistematicamente o domínio dos entes.

Ao abordarmos as possíveis contribuições da filosofia de Heidegger à educação, pretendemos inferir sobre tal possibilidade, tendo em vista que não há menção explicita em seus escritos sobre estes aspectos, ainda que seja bem conhecida sua atuação na docência universitária. Neste contexto, o desenvolvimento das interpretações hermenêuticas tem como ponto de partida a gênese ontológica do conhecimento técnico-científico. A educação tecnicista induz ao processo produtivo que afasta o pensamento questionador, contudo, o modo de questionar pode revelar a sua natureza de forma adequada. Para compreendermos a temática em questão, faz-se necessário identificar tais significações. O modo como perguntamos pode indicar quais caminhos reflexivos foi percorrido ao longo de determinado tempo (ZIMMERMAN, 1990).

Zimmerman (1990) apresenta três significados inter-relacionados ao pensamento tecnicista e a técnica em Heidegger, quais sejam: industrial, associada em geral a instrumentos, sistemas e processos de produção em geral; científico, ligada a posição racionalista, mercantilista, utilitarista, antropocêntrica e secular; moderno, o modo de compreender e de revelar as coisas, o qual torna possíveis os processos de produção industrial com todas as suas ideias de apoio. Esse último significado se destacaria em Heidegger por se constituir em sintomas da revelação 
das coisas como tais. Para o educador-filósofo, as coisas se revelam como matériaprima não de acordo com uma decisão humana, mas como algo que se revela na história do ser.

Deste modo, o significado moderno da técnica aponta à revelação das coisas, distinguindo-se do significado industrial da técnica que se expressa nos processos industriais e instrumentos técnicos. No contexto da técnica moderna, Heidegger concebe que a tarefa do questionamento reflexivo é de descobrir e desocultar as condições teóricas, os princípios, os conceitos epistemológicos que tornam viáveis a elaboração do conhecimento e à implementação das ações humanas. Aquilo que tem sido denominado moderno, não é um modo definitivo que possa explicar pelo princípio de causa e efeito a situação de algum tempo posterior, pois é, antes de tudo, o sintoma de algo mais profundo, iniciado com a metafísica de Platão e culminando na era da técnica moderna (DUBOIS, 2004).

Na Conferência "A época da imagem do mundo"(1938), Heidegger traz sua reflexão sobre a essência dos tempos modernos, a partir do questionamento sobre o mundo atual, tratando da questão da técnica. O que faz da concepção do mundo dos tempos modernos algo totalmente distinto das concepções do mundo medieval e antiga. No caso da modernidade, entre os fenômenos pelos quais os sinais do tempo são vestígios seguros da metafísica e que a sustentam, encontramse: a técnica, a ciência, a arte, a cultura (HEIDEGGER, 2005).

Neste contexto, a ciência deve ser compreendida no sentido moderno, sendo essencialmente diferente da doutrina medieval e da epistêmê antiga. Considera que certa época histórica se caracteriza com relação à essência do ente e à essência da verdade instituídas metafisicamente. A meditação sobre a essência técnica permite compreender a ciência moderna como um fenômeno determinante da história do ser. Dito de outra forma, esta essência é plenamente histórica, manifestando o traço decisivo de certa época moderna. Desde Platão e Aristóteles inicia-se uma época no ocidente, cuja tendência foi a de demarcar e firmar um acordo sobre uma interpretação a respeito do ser(DUBOIS, 2004).

A tendência à técnica começou já na Antiguidade. Essa indicação nos remete às questões das interpretações de ente e a delimitação do ser. Essa 
delimitação do ser como sujeito referido ao cogito com a postulação do método para indicar a existência e a veracidade do ente é reafirmada e ampliada na idade moderna, inicialmente com Descartes. Com ele a definição do ente se restringe às permissões do cogito quando ao pensá-lo apenas importa considerar a possibilidade da mensuração e do cálculo.

O método inicialmente apresentado por Aristóteles para se obter o conceito dos entes, e que se voltava para a obtenção de sua essência ou substância, são alterados em favor da observação, classificação, generalização, previsão e controle dos entes. $\mathrm{O}$ que puder ser apreendido por esse processo metodológico é então reconhecido como real. O que resulta de tal processo é o pensamento calculador, é outra coisa do que o pretenso conceito buscado na antiguidade grega. O fim desse novo processo é identificado como a representação do ente com as possibilidades do cálculo da razão.

Para Heidegger, o que opera em relação ao real é um controle sobre sua possibilidade de manifestação, de maneira que em toda parte impera a interpelação provocadora, asseguradora e calculadora. A esse poder de interpelação produtora está subordinado tudo o que é e pode ser: o existir diário dos homens, as ciências, a indústria e a economia (HEIDEGGER, 2006).

Quanto às condições de possibilidade da técnica moderna, Heidegger tem uma tese fundamental, isto é, que essas condições são de natureza metafísica. A técnica industrial mecanizada é até aqui o prolongamento mais visível da essência da técnica moderna, a qual é idêntica à essência da metafísica moderna (HEIDEGGER, 2006).

A técnica designa no contexto da palavra grega téchne, uma modalidade de saber e de conhecimento na produção. Técnica é hoje, essencialmente, uma modificação pelo fazer e pelo agir humano. O termo produzir significa conduzir algo à sua manifestação, de modo a tornar acessível e disponível o que, antes disso, ainda não estava aí presente. Produzir se realiza, de modo singular no ocidente europeu, por meio do desenvolvimento das modernas ciências matemáticas da natureza. 
Na Conferência "A Questão da Técnica" (Munique, 1953), em que Heisenberg estava presente, Heidegger tratou dos questionamentos sobre o caminho do pensamento, da linguagem e da abertura do existente humano à essência técnica. Nessa ocasião Heidegger faz menção a Heisenberg e a sua Conferência "A Imagem da natureza na física moderna" realizada ainda em 1953. As circunstâncias e o pensamento humano de tal maneira que Heidegger reafirma o desligamento da pergunta pela técnica da questão da instrumentalidade e do agir instrumental. O problema da técnica não é o da instrumentalidade, nem mesmo a causalidade implicada pela instrumentalidade, mas o modo de desocultamento, da verdade do ser (HEIDEGGER, 2006).

Heidegger compreende como sendo a essência da técnica moderna, o que às vezes é confundida com a essência da ocidentalidade. Ela não é apenas um modo de pensar, mas um modo de ser que nos caracteriza enquanto civilização ocidental. Na época atual, a humanidade do homem, que se estabeleceu sobre a razão calculadora, se amplia e sobrepuja na figura da técnica. A técnica é constituída como o modo de existir do homem. Assim somos impelidos pela técnica a nos lançarmos à frente comopossibilidade e requisição no contexto da ocidentalidade.

Neste sentido, então o que seria pensável na era das incertezas e da técnica à melhoria do ensino de ciências? Tendo em vista que Nardi (2008) trata da existência e persistência de concepções tradicionais que os docentes possuem sobre a ciência e dos processos de ensino e aprendizagem, cabe-nos encontrar estratégias de provocação à reflexão sobre o exercício da docência. Conforme Hewson, uma estratégia importante para a qualificação da docência em ciências é o acréscimo da dimensão histórico-filosófico a fim de superar a imagem distorcida e fragmentada da atividade científica. Ele ainda menciona o fato que:

A visão positivista sobre a construção do conhecimento científico implica na adoção de metodologias de ensino baseadas na transmissão e recepção passiva de conhecimentos considerados como verdadeiros e imutáveis, dificultando aceitação de metodologias inovadoras (HEWSON, 1999). 
Assim sendo, a concepção tradicional de ciência pode ser revisada à luz de novas contribuições de outras áreas do saber. Desta forma, as ciências humanas, particularmente a filosofia, tecem reflexões oportunas para que novos olhares direcionem o debate à análise dos conceitos, dos fundamentos e dos estatutos científicos, de modo a ampliar os horizontes da compreensão sobre o conhecimento e às ciências da natureza expressas através da linguagem.

Conforme Moreira (2011), citando Postman e Weingartner, a linguagem está longe de ser neutra no processo de perceber bem como no processo de avaliar nossas percepções. Acostumamo-nos a pensar que a linguagem expressa nosso pensamento e que ela reflete o que vemos. E ainda, a linguagem está totalmente implicada em qualquer $e$ em todas as tentativas de perceber a realidade. A linguagem, segundo o mesmo autor, é conhecimento. Para ele, a chave da compreensão de determinado conhecimento ou conteúdo é conhecer sua linguagem. Ensinar biologia, matemática, história, física, literatura ou qualquer outra matéria é, enfim, ensinar uma linguagem, um jeito de falar, um modo de ver o mundo. Se o conhecimento é uma linguagem, a chave da sua compreensão se dá na interação do compartilhamento dos conceitos e dos seus significados (MOREIRA, 2011).

Nesta mesma perspectiva, Novak afirma que:

Os processos psicológicos através dos quais um indivíduo constrói os seus significados são essencialmente os mesmos que os processos epistemológicos através dos quais o novo conhecimento é construído pelos profissionais numa determinada disciplina... criar um novo conhecimento é, por parte do seu criador, uma forma de aprendizagem significativa (NOVAK, 2000).

Segundo Heidegger, é pela linguagem que o homem acede ao mundo da existência. A linguagem é uma possibilidade particular dada ao homem e uma determinação essencial do seu ser. Ela é um modo de ser e uma estrutura da existência. "O homem não é um animal que possui a razão(zdôon logon echon), mas um ser que é possuído pela linguagem” (RESWEBER, 1979). 
Conclusão

A presente revisão bibliográfica teve como propósito analisar as reflexões de Heisenberg sobre a ciência e natureza, no contexto da fundação da teoria quântica, e da abordagem de Heidegger à questão da técnica, verificando-se suas concepções sobre a formação do conhecimento científico e educacional em decorrência do existente humano. Assim sendo, Heisenberg verificou que no projeto prévio das observações da natureza o cálculo das forças supostas na movimentação dos objetos, no transcurso do tempo e do espaço, possibilitou, desde Galileu, a determinação científica de certas regularidades e de relações na natureza.

Desta maneira que o cientista pretensamente observa de modo neutro os fenômenos da natureza de acordo com hipóteses amparadas na coerência matemática.

Diferentemente da física clássica, em que a representação moderna da natureza se faz pela descrição matemática compilando informações sobre leis naturais a partir de projeção prévia. Entre as mais significativas modificações ocorridas na conceituação de lei da natureza encontra-se a relativização do tradicional princípio de causa e efeito, com o qual contavam tanto Galileu quanto Newton, e que na física quântica se tornou incompatível. O observador perde o seu ponto arquimédico neutro, pois interfere com a sua atividade de metrificação no objeto da sua investigação.

$\mathrm{Na}$ física atômica a teoria como elemento metodológico e a hipótese não mais se baseiam no sentido ontológico, e, então, a incerteza integra-se ao processo de investigação. Ocorre aí uma radical mudança quanto à concepção de objetividade no conhecimento científico, de modo que a manutenção da distinção sujeito-objeto se torna desnecessária. A objetividade da natureza material apresenta, na física atômica moderna, característica fundamental completamente diferente da física clássica. A física atômica, apesar de toda a sua diferença em relação à física clássica, dá indícios de permanecer alinhada com a física em geral, conforme diz Heisenberg: "a possibilidade de escrever uma única equação 
fundamental, da qual decorram as propriedades de todas as partículas elementares e com isso o comportamento da matéria em geral" (HEISENBERG, 1990).

Há, portanto, um elemento que não muda na passagem da física clássica para a física atômica. Esse elemento é que a natureza de antemão se apresente a um asseguramento calculador, realizado pela ciência por meio da teoria. Com esse raciocínio temos como que uma complementação de dois campos, isto é, de um lado, a natureza que se presta antecipadamente à permissão do asseguramento e, de outro, a ciência que busca assegurar este mesmo domínio por meio da teoria.

Instala-se então o princípio da incerteza na física quântica. De acordo com o mesmo, os elementos últimos da matéria não mais podem ser considerados "em si" como realidade objetiva, pois, nas medições quânticas, em qualquer instante a indeterminação impossibilita o estabelecimento tanto do momentum, quanto da localização de uma partícula atômica. Assim, as previsões sobre o que ocorre dependem então de cálculos probabilísticos, apresentando dificuldades descritivas só superáveis pela matemática. Entretanto, os resultados da física atômica não anulam a física moderna, mas a incorporam como dados de conhecimento de uma natureza inesgotável, conforme Heisenberg. A época da técnica em sua progressividade transformou as circunstâncias e o pensamento de ser humano de tal modo que ele parece encontrar-se a si mesmo em todo o lugar.

Deste modo verificou-se esta concepção conta com o existente humano como ser-no-mundo, já sempre junto aos entes ao modo da compreensão. Na condição de ente privilegiado em poder perguntar pelo ser e compreender os outros entes, o projeto prévio necessário à atividade científica é uma das possibilidades deste existente humano. Como seu comportamento, a ciência e a técnica são modos de conhecimento específico pelo qual se relaciona com os entes. A essência fundamental do ser humano, porém, não deixa de ser a transcendência num constante tornar-se essencial em meio ao questionar expresso, inclusive sobre as condições de possibilidade técnico-científica num projeto previamente fundamentador à base de uma rede conceitual.

Outro dado fundamental, que para Heidegger se apresenta insofismável, é o fato de que a ciência física depende sempre previamente da vigência da natureza 
em sua plenitude e jamais poderá contornar esta situação. O incontornável para a ciência é, portanto, a própria natureza. Assim, a delimitação prévia teórica da ciência e da técnica impede o seu acesso ao todo da natureza, isto é, a natureza é também inacessível à ciência e a técnica, na qual se limita a se apresentar como teoria e método. Por fim, deve-se registrar que a abordagem heideggeriana apresenta considerações sobre temas e problemas que podem ser relevantes para o vasto e concorrido campo de estudos atuais do conhecimento científico.

Conforme Nussbaum, a evolução da abordagem construtivista na educação da ciência está sendo alimentada pelos novos desenvolvimentos na história e filosofia da ciência, que mudou a imagem clássica da ciência. De acordo com a nova imagem, a ciência está sempre empenhada em construir e reconstruir modelos tendo em vista aumentar a nossa compreensão da natureza, mas que nunca podem representar a verdade absoluta (NUSSBAUM in NOVAK, 2000).

Cabe-nos então atentar ao que diz Heidegger: "aprende-se na medida em que se traz o fazer e seu deixar ser humano à correspondência do essencial em cada caso. Aprendemos o pensar no atentar ao que é pensável" (1984). O pensável está relacionado às possíveis ações pedagógicas. Isso quer dizer que aprender a pensar a educação a partir das contribuições de Heidegger e de Heisenberg quanto às mudanças ocorridas no mundo das ciências naturais e do seu impacto no cotidiano educacional, sob a perspectiva da construção do conhecimento científico a partir da compreensão dos fenômenos verificados no cotidiano.

\section{REFERÊNCIAS}

BOHR,N.H.D. Física Atômica e Conhecimento Humano: ensaios 1932-1957. Rio de Janeiro: Contraponto, 2000.

CACHAPUZ,A.et al. A Necessária Renovação do Ensino das Ciências. São Paulo: Editora Cortez, 2011.

CAPRA,F. The Web of Life. São Paulo: Editora Cultrix\&Amana-Key, 1996.

CASSIRER,E. Antropologia Filosófica: Ensaio sobre o Homem. São Paulo: Editora MestreJou Ed., 1972.

DUBOIS,C. Heidegger: Introdução a uma Leitura. Rio de Janeiro: Jorge Zahar Editora, 2004. 
EISBERG,R. e RESNICK,R. Física Quântica. Rio de Janeiro: Editora Campus, 1979

GASIOROWICZ,S. Física Quântica. Rio de Janeiro: Guanabara Dois Ed., 1979.

Vozes, 2007.

GLAZEBROOK,T. Heidegger's Philosophy of Science. New York: Fordham University Press, 2000.

HEIDEGGER,M. Ensaios e Conferências . Petrópolis:Editora Vozes,2006. . Introdução a Filosofia. Petrópolis: Editoras Vozes, 2009.

. Phänomenologische Interpretation von Kants Kritik der Reinen

Vernunft . Frankfurt am Main:Vittorio Klostermann Ed.,1995.

Ser e Tempo. Petrópolis: Editora Vozes, 2006.

The Concept of Time in the Science of History. Suplements:

From the Earliest Essays to Being and Time and Beyond in Martin Heidegger. New York: State University of New York Press, 2002.

HEISENBERG,W. Física e Filosofia. Brasília: Editora da Universidade de Brasília, 1981.

do Brasil, 1980.

A Imagem da Natureza na Física Moderna. Lisboa: Ed. Livros

Universitária,

A Ordenação da Realidade. Rio de Janeiro: Ed.Forense

2009.

$\overline{\text { Publicações, } 1990 .}$

Páginas de Reflexão e Auto-retrato. Lisboa: Gradiva

Problemas da Física Moderna. São Paulo: Ed.Perspectiva, 2006. HEMPEL,H.-P. Natur und Geschichte Der Jahrundertdialogzwschen Heidegger und Heisenberg. Frankfurt/Germany: Verlag Anton HainMeisenheim GmbH, 1990. HERMANN, A . Werner Heisenberg: 1901 - 1976. Hamburg / Germany: Rowohlt TaschenbuchVerlag GmbH, 1976.

HEWSON, P.W. et al. Educating prospective teachers of Biology: introduction and research methods. Science Education, 33 (1).1999.

KOCHE, J. C. Fundamentos de Metodologia Científica. São Paulo: Editora Vozes, 1982.

LOGUERCIO, R. Q.; Del Pino, J. C. Contribuições da História e da Filosofia da Ciência para a Construção do Conhecimento Científico em Contextos de Formação Profissional da Química. Acta Scienteae, V. 8, n. 1, p. 67-77, 2006.

LOPES, C. V. M.; Kruger, V. Souza, D. O.; Del Pino, J. C. Concepções de Professores de Química sobre a Natureza do Conhecimento Científico. Acta Scienteae, V. 9, n. 1, p. 3-16, 2007.

MATURANA, H. R.\& VARELA, F. De Máquina a Seres Vivos: Autopoiese, a Organização do Vivo. Porto Alegre: Artes Médicas, 1997.

MOREIRA, M.A. Aprendizagem Significativa: Teoria e Textos Complementares. São Paulo: Editora Livraria da Física, 2011.

MORTIMER, E. F. O Significado das Fórmulas Químicas. Química Nova na Escola, $\mathrm{N}^{\circ} 3$, p. 19-21, 1996.

NUSSBAUM, J. in NOVAK, J. et al. Ensinando Ciência para a Compreensão: uma Visão Construtivista. Lisboa: Edições Técnicas, 2000. 
NOVAK, J. et al. Ensinando Ciência para a Compreensão: uma Visão Construtivista. Lisboa: Edições Técnicas, 2000.

POPPER, K.Conjecturas e Refutações. Brasilia: Livraria Universitária de Brasília (UNB), 1982.

RESWEBER, J.P. O Pensamento de Martin Heidegger. Coimbra: Livraria Almedina, 1979.

SANTOS, B. S. Um Discurso sobre as Ciências. Porto: Afrontamento, 2002.

SAFRANSKI, R. Heidegger: um Mestre da Alemanha entre o Bem e o Mal. São Paulo: Geração Editorial, 2000.

ZIMMERMAN,M .E. Heidegger's Confrontation with Modernity. Technology, Politics, Art. Bloomington: Indicano University Press, 1990. 